\title{
Problem-based learning: the emergence of new scripts and roles for teachers to render epistemic practices transparent.
}

\author{
Karen Jensen \\ Helge I. Strømsø \\ University of Oslo
}

Corresponding author: Karen Jensen, Department of Education, University of Oslo, Box 1092 Blindern, 0317 Oslo, Norway. Email: karen.jensen@iped.uio.no 


\begin{abstract}
A lack of alignment between professional practice and education has triggered the move to alternative educational models, often with detailed scripts and templates to be followed. Among these are variants of problem/case-based models, where learners are challenged to achieve professionally desired learning outcomes and acquire knowledge and skills in their respective disciplines by encountering real-life situations as the stimulus and focus of their learning activities. A characteristic of these diverse models is that their scripts have been based on theories and understandings of what constitutes good learning and teaching. This article reports on a study conducted among law students that uses a script which focuses on the core 'know-how' of the legal profession. To examine the merits of this approach with respect to actionable knowledge, we employ perspectives from Knorr Cetina's practice-theoretical lens. Particular attention is paid to how students are introduced to and learn the three archetypes of epistemic practices that Knorr Cetina identifies as central for members of expert cultures. The results from the study not only show that these practices were developed but also detail what is important in this respect. Thus, the article addresses calls in this journal for more research on how connections between school and work for professionals can be enhanced.
\end{abstract}

Keywords: problem-based learning; epistemic practices; legal education; comparative optics; teachers' guidance

\title{
Introduction
}

Preparation for professions has been part of university missions for a very long time. Professional education is of great importance to universities and plays a significant role in shaping questions about the purpose of the institution. However, in the past 20 years, many university schools and faculties seriously engaged in professional education have made efforts to better integrate workplace experience and academic study (Billett and Choy 2013). Although professional education at universities in domains like law and medicine has included elements of workplace experience for more than a century, the alignment of subject matter and clinical work continues to be a challenge. Within the domain of law, a widespread approach to overcome this challenge has been the implementation of the case-based learning (CBL) method. This classic case method was developed at Harvard Law School in 1870 and was intended to combine the then commonly used methods of lecturing and apprenticeship (Williams 1992). Students were presented with selected court cases and instructed to prepare a summary of them for a teacher-led, large-group discussion. In class, students presented their summaries and were 
questioned by the professor, who was assumed to follow a Socratic approach in examining students' understanding and position regarding the case. This method is still popular in law schools and has also been applied to other domains (Loyens and Rikers 2011; Williams 1992).

Problem-based learning (PBL), most commonly used in medical education, could be regarded as a prominent example of case-based instruction (Williams 1992), although some would argue that it is the other way around (Barrows 1986). During recent decades, PBL has made substantial inroads into professional preparation programmes (Boud and Feletti 1997; Schmidt et al. 2011). However, as pointed out by Barrows (1986), the term PBL may have several different meanings depending on the educational method employed. A common feature is the introduction of a problem, most often represented by a complex and ill-structured case, intended to situate learning in a meaningful context. In the prescribed PBL programme, students are introduced to the problem in small groups facilitated by a teacher and follow a step-by-step procedure in analysing the case and generating hypotheses, identifying knowledge gaps, maintaining self-directed learning and applying new knowledge to solve the problem (Barrows 1986; Hmelo-Silver and DeSimone 2013). Together with some other approaches, such as challenge-based learning (O’Mahony et al. 2012), CBL and PBL represent different kinds of inquiry learning. For reasons of simplicity, and in accordance with Barrows (1986), we will refer to such models of teaching and inquiry learning by using the PBL label.

While the many forms and flavours of PBL curricula, programmes and courses make it increasingly difficult to evaluate, compare and generalise the findings from studies related to PBL interventions (Newman 2003), there is abundant evidence to suggest that if PBL is well-implemented and provides effective support, it may enable students to form a cognitive apprenticeship (Hmelo-Silver et al. 2007, p. 101).

However, to become a practitioner in a professional field, a novice learner must serve both a cognitive and a practical apprenticeship (Schulman 2005). In the former, a person learns to think like a professional; while in the latter, Shulman contends, one learns to perform like a professional, i.e., the learning of skills, techniques and practices is essential for preparing students with knowledge for action. ${ }^{1}$ Several important suggestions have already been made in the literature about how practical apprenticeships might operate and the various ways in which workplaces may be organised to better exploit their potential as sites for learning (Akkerman and Bakker 2012; Billett 2001, 2010; Guile and Griffiths 2001). Through the qualitative study reported in this article, we attempt to show how a PBL course can be designed and implemented to serve as a practical apprenticeship. Our main focus will be on determining what can be done to

\footnotetext{
${ }^{1}$ Shulman characterizes professional education more generally as a synthesis of three apprenticeships. The third being a moral apprenticeship; i.e.to think and act in a responsible and ethical manner.
} 
maximise the advantages of a PBL session so that it can become a format for preparing students to perform like professionals. The five -day law course in question emphasised basic legal know-how. A complex legal case was used to introduce students to the core practices involved in resolving legal problems and to the various legal sources they should consider in this respect. Thus, it involved a different script ${ }^{2}$ from that of the traditional PBL - rather than being designed in accordance with the characteristics of learning, its design was based on the structure of professional know-how.

To further address this issue with respect to our study, concepts from Knorr Cetina's theory of practice are employed. An epistemic practice focuses on the practical 'know-how' of knowledge, which is specialised for a contextual purpose. An epistemic practice is defined as one aimed at processes of approaching, safeguarding and applying knowledge. In this article, we explore the three archetypes of epistemic practices that Knorr Cetina identified as central for members of professional cultures to learn (Knorr Cetina and Reichmann 2016). These archetypes constitute the core know-how of professional work, but they may be partially tacit and must therefore be made explicit if prospective learners are to acquire them. Hence, our research contributes to the PBL literature by focusing on what Hoidn and Kärkkäinen (2014, p. 21) described as "new initiatives and studies that strategically and proactively bridge PBL research and practice'.

The article is organised as follows. The next section outlines in more detail a set of conceptual notions that underpin the epistemic practice lens. Then, the empirical context is presented, and three key research questions are identified. This is followed by a section on methods. The findings are then presented through a day-by day structure to provide detailed insight into how the course works as a possible practical apprenticeship. The article concludes with a discussion of our results and how they contribute to our understanding of the value of PBL in aligning education and work.

\section{An epistemic practice lens}

In the practice-theoretical perspective developed by Knorr Cetina, one key assumption is that a given field of expertise (such as the legal profession) is characterised by shared conventions for approaching, developing and sharing knowledge. These conventions comprise orders of meaning. For Knorr Cetina, it is these conventions or orders of meaning which make professional life possible and functional by defining 'how we know what we know' (Knorr Cetina (1999) p1). In line with this, knowledge, facts

\footnotetext{
${ }^{2}$ The term "script", borrowed from science and technology studies (STS), designates the vision of what and the program of action a technology is supposed to accomplish (Akrich and Latour, 1992)
} 
and ways of approaching problems are not given but seen as maintained in often-fragile structures of meaning. It is these fragile structures or orders of meaning which are meant by practice. In this vein, Knorr Cetina identified three practices as critical to understanding how a profession functions (Knorr Cetina and Reichmann 2016) and are hence essential to prospective professionals. It is important to note that the core practices are not generic. Rather, they are entwined with the epistemic frameworks and orders of meaning of a particular epistemic culture. Hence, while we use illustrations from law, these practices play out differently within different professions, suggesting that they must be studied in their specific contexts.

First, professionals must discern what is and is not relevant information for the situations they find themselves in. Only when they have done so can they effectively identify the type of problem they are dealing with and begin the process of resolving it. Thus, professionals need to engage in practices related to sorting - or what Knorr Cetina termed distinguishing - 'signal from noise'. For lawyers, as for other expert groups, it is only possible to speak confidently about problems after they have been rearranged in a specific way in light of the issues to be resolved and the tasks to be completed. The second core practice is establishing relevant resource relationships and deciding which figures to trust. As with all types of expert knowledge, professional knowledge is collective - what we know comes primarily from others, and knowing whom to trust and what to believe is essential. Hence, professions are typically infused with strategies and epistemic practices designed to ensure trust in knowledge. The third core practice is that of incorporating knowledge-related principles learned in various settings into practical work - what Knorr Cetina would describe as moving from in vitro experimentation to in vivo actions. With respect to the legal profession, this practice reflects how jurists are expected to incorporate the whole 'genesis' of law in legal decision making (Latour 2010).

The practices outlined above are important for both novice and experienced practitioners when they are exposed to the complex mixtures of knowledgeability found in workplaces. However, these practices may be partially tacit and need to be made explicit through presenting practices. Following Knorr Cetina, epistemic practices can be analysed in two ways - with respect to how they assemble and how they represent. As Pels (2000, p. 1) suggested, representation can be understood as 'presenting' that which is not immediately at hand, that which is absent and therefore must be introduced into the present situation to be rendered visible and available in context. In short, this perspective (i) highlights the importance of the three core practices and shows how mutually distinct they are; (ii) draws attention to the 'nested' nature of these practices, i.e. one must acquire them in sequence; (iii) arguably underlines the need to investigate the skills required to access the different forms of practice (i.e. know-how with respect to trusted sources needs to build on skills and familiarity with the attributes of various materials); (iv) implies a transformed understanding of agency, i.e. students and teachers are not 
viewed primarily as constructors but rather carriers of core practices. Thus, identifying how prospective professionals can best be guided such that they learn these practices within an overall course structure is critical when devising professional education programmes.

We suggest that the epistemic practice perspective provides a basis for delineating three key research questions: (1) Is the design of the course configured to facilitate students' understanding and adoption of the three core epistemic practices? (2) What is the teacher's role in externalising the ordering structures of the legal profession and making them transparent? (3) What is the relational dynamic between what the students are introduced to and what they explore in their groups?

\section{Method}

To explore these research questions, we draw on data gathered within the frame of a larger project in which we compared and contrasted the introductory courses in three professional programmes in Norway. With respect to legal education, the focal course was the five-day introductory course. In comparing and contrasting the courses in the larger project, we noticed that this particular course had some notable design-related features and a noteworthy implementation scheme (Damşa, et.al. 2017). As mentioned earlier, the design focused on the core know-how of the profession. With respect to implementation, it was an up-scaled course in which the tutor's role had been radically reduced owing to a lack of resources, and no teacher attended the group sessions. Hence, we decided to examine in detail how the facilitation provided in large seminars works at a distance, i.e. how students discuss and act on teacher inputs in their independent group processes.

\section{Participants}

In the introductory law course, students are divided into 34 teacher-led colloquium groups, with each group comprising 12-16 students. The teacher-led sessions run two hours per day over four days followed by a final summary seminar. Between the sessions, the students are expected to work on the vignette presented, both in small groups (four to six) and individually. A convenience sampling procedure was used to recruit teachers and students who were willing to accept the sessions being videotaped. Three groups led by three different professors agreed to participate. All three professors hold $\mathrm{PhD}$ degrees in law and have varying levels of teaching experience in Norway and abroad. To illuminate different patterns regarding how epistemic practices were introduced by teachers and applied by students within the frame of the overall course design, initial observations of the teacher-led sessions and students' work in small groups were used to purposively 
select participants to be included in the analyses. Teachers and groups that seemed to most clearly display different patterns were selected for the final sample.

Based on this procedure, the final sample consisted of two teacher-led seminars and two small student groups (one from each of the teacher-led seminars). The groups consisted of 4-6 members. Both the seminars and the small group meetings were organised four times during one week.

\section{The scenario}

The scenario presented to the students was a vignette about a young couple (Tine and Hallvard) who borrow money to buy a used car, which then breaks down on their way to a pre-paid vacation. The salesman, Gabriel, agrees to repair the vehicle, but it will take a few days. To avoid wasting more of their holiday, Hallvard and Tine buy inexpensive plane tickets and travel to their destination. After returning, Hallvard uses the car for a trip with some friends to a cabin. He parks outside the cabin and leaves the keys in the ignition. A 17-year-old boy takes it for a 'test drive', but his trip ends when the car goes off the road and the vehicle is damaged. Tine ends her relationship with Hallvard. To safeguard herself and her mother from financial loss, she demands that Hallvard takes full responsibility for not only repairing the car but also buying it from her. Thus, the scenario contains many actors and several disputes and is interwoven with details that are more or less relevant from a legal perspective.

\section{Course delivery}

During the course, the students were introduced to a new epistemic practice each day, which they were expected to consider while analysing the scenario. The teacher-led sessions ran for two hours per day with 24-30 students. Thereafter, the students were expected to work on the scenario between sessions, both in small groups and individually. The student meetings typically lasted two hours and on each subsequent day their work was briefly discussed and commented on by the professors leading the sessions prior to the presentation of the next practice. The week ended with a plenary lecture for all students in which one of the teachers worked through the case and its possible claims and arguments.

\section{Procedure and materials}

The teachers were not left to their own devices. They had pre-meetings to discuss their aims and instructional strategies, and their work was supported by a schedule provided by the course leader which described what topics and legal sources should be highlighted during the various sessions. Time was also allocated for sharing experiences 
from previous teaching years and offering advice in terms of student guidance. To offer additional support for the teachers, an article discussing the status of the various legal sources was supplied. Thus, the teachers were introduced to a rather tightly-scripted task that had been defined collegially.

In the context of the larger project, we had videotaped three teacher-led sessions (10 hours per colloquium). Furthermore, one of the student groups in each colloquium agreed to videotape their independent group discussions during the week. This material comprised 16 hours of videotaped recordings of the students' group work. As supplementary data, two plenary lectures, which were held at the beginning and end of the week, as well as a pre-meeting attended by the course teachers, were observed. Further, we collected course documents and copies of the materials the students were introduced to (an overview of data used in the analysis is displayed in Table1 below).

\section{Table 1}

Overview of data used in the analysis

\begin{tabular}{|c|c|c|c|}
\hline & $\begin{array}{l}\text { Teacher-led } \\
\text { Colloquiums }\end{array}$ & $\begin{array}{l}\text { Student Group } \\
\text { Discussions }\end{array}$ & Other Materials \\
\hline $\begin{array}{l}\text { Participants in the } \\
\text { study }\end{array}$ & $\begin{array}{l}2 \text { groups of } 12-16 \\
\text { students led by a } \\
\text { professor }\end{array}$ & $\begin{array}{l}2 \text { student groups of } \\
4-6 \text { students (one } \\
\text { from each of the } \\
\text { teacher-led } \\
\text { colloquiums) }\end{array}$ & \multirow{3}{*}{$\begin{array}{l}* \text { Observations of } \\
\text { the preparatory } \\
\text { meetings for } \\
\text { teachers in the } \\
\text { course } \\
\text { *Observation of } \\
\text { final plenary lecture } \\
\text { (notes, PPT's) } \\
\text { *Course documents, } \\
\text { case descriptions, } \\
\text { legal sources }\end{array}$} \\
\hline Type of data & $\begin{array}{l}\text { Video-taped } \\
\text { participant } \\
\text { observations }\end{array}$ & $\begin{array}{l}\text { Video-taped group } \\
\text { meetings, } 4 \\
\text { meetings per group } \\
\text { (recorded by the } \\
\text { students) }\end{array}$ & \\
\hline Amount of data & $2 \times 10 \mathrm{~h}$ & $16 \mathrm{~h}$ & \\
\hline
\end{tabular}

\section{Our approach to analysis}

Our analytical strategy was guided by our research questions and was performed in several stages. First, one of the authors reviewed the videotapes from the two student groups to identify key steps in their problem-solving process, with a particular focus on episodes during which students found it difficult to move forward in their exploratory 
work. Thereafter, the recordings obtained from the teacher-led sessions were analysed with respect to what issues the teachers had highlighted.

To explore in more detail the relational dynamic between teachers' inputs, the overall course design and students' progression, we employed what Knorr Cetina (1999) called a comparative optic. Rather than aiming at a strict comparison, this approach entails examining one case in the light of another as an analytical strategy. The strength of this particular approach lies in its concern for what is produced through specific aspects of the course and teaching practices as opposed to attempting to determine what is best up front. The analysis follows the same themes and steps for each of the two PBL groups, comparing and contrasting them; that is, the way the students were introduced to the three core practices, how teachers' inputs were picked up and used in the students' discussions; how the student groups approached and interpreted the task; the actions they took to address the task; and lastly, how the students' practices and solutions to the scenario changed over the week. Of special interest was the identification of factors that that seemed particularly beneficial for students' progress.

To check the reliability of our analysis and minimise the impact of a single author's preconceived notions, we consulted researchers who had gathered and analysed data for the larger comparative project mentioned earlier. We had several meetings in which we compared our interpretation with theirs and established that we had a common understanding of the identified group differences.

In what follows, the work completed by the groups is presented sequentially (i.e., Group 1 before Group 2), and core challenges are then discussed. To illustrate the relational dynamic between the overall course design, the teachers' input and the students' progression, we followed the day-by-day structure of the course and captured vivid episodes that show how the different groups worked and progressed. To preserve the anonymity of the teachers and students, we concealed the teachers' gender, referring to both as 'he', and we used numbers (S1, S2, etc.) to identify the students. The quotes from participants are transcribed verbatim from the video recordings but in some cases the dialogue has been condensed for the sake of brevity.

\section{Findings}

\section{Group 1}

\section{Day 1: Distinguishing signal from noise: Sorting the case}

The first teacher-led session begins with introductions. Everyone describes why they applied to law school and the expectations they have. The teacher uses the students' 
aspirations as a point of departure to discuss what law is and what law is not. He indicates that, by its very nature, the law possesses distinctive features, and lawyers look at the world in a unique way. Furthermore, the teacher explains that not all arguments have equal value. For arguments to hold up in the world of law, they must be grounded in legal sources, and different sources carry different weights. In professional jargon, this is called 'types of authority'. One of the goals of the course, he says, is to provide an understanding of the various types of authority and broad principles that operate in this specific type of system.

He continues by identifying the two core issues that are critical to the daily work of lawyers. The first is the need to 'sort the cases' and reconfigure problems to make them 'solvable'. He then presents the students with a systematic way of analysing a legal case. This involves a step-by-step procedure for identifying the actors, claims and disputes in the factual scenario. The second issue is to explore the scenario in light of the students' personal experience and general sense of right and wrong.

\section{Student work}

When examining the group work we find that, before meeting, the students had individually sorted the case in line with the directions provided by the teacher. Hence, they had already eliminated much of 'the noise' in the story, and they all more or less identified the following parties: Hallvard and Tine can make a claim against Gabriel (the car salesperson); Hallvard and Tine can make a claim against the boy (and his parents); and Tine (and her mother) can make claims against Hallvard.

This enabled the students to proceed in a structured manner. The students began by examining Hallvard's and Tine's positions. In the heated arguments that ensued, their debate was mediated by their moral opinions regarding what was fair and just. The following excerpts illustrate how this task engaged the students and contributed to their progress:

S1: Now that the case is sorted, we should go to the next step.

S3: Ok. In our discussions, we'll approach the different issues on the basis of what we think is reasonable, because so far that's all we have.

S5: But it's very exciting that we have different views on the case.

S1: Yes, yes, I think that's very good, too.

S5: I must say that when I heard your arguments, I began to agree that Gabriel (the car salesman) should pay. However, the first time I read the case I thought that Tine and Hallvard definitely had ... Well, hit the buffers!

The day closes with the students wondering about how the law could help to discern 'whose fault it was that the car broke down'. 
In summary, we can observe how, following the teacher's clear directions, sorting the case and eliminating some of the 'noise' at an early stage of their work enabled the students to make valuable progress in their evaluation of the scenario. In the legal profession, the practice of sorting is integral to reasoning and involves identifying what facts, arguments and legal precedents are relevant. It is not a one-off event and, when considering subsequent days, we will see that this practice was critical to approaching the scenario in a productive manner.

\section{Day 2: Figures to trust: Legislators}

In the teacher-led session the next day, the students' work is discussed and commented on. Attention then turns to statutes as legal sources. The teacher explains that identifying the parties and claims is only the first step. All of these claims must be further investigated before their legal status can be determined. We see that Teacher 1 again advocates structure and precision as the driving criteria for good work. He ends the session by providing further cues regarding how to sort the issues: 'Before looking for

law, you have to identify what is at the core of the case. What factor does everything else hinge on?'

\section{Student work}

In the subsequent group discussion, one of the students suggests that the group should take one claim at a time and find laws that address the issues. Furthermore, the student suggests that they should begin with questions relating to the circuit board because it is 'the premise for everything'.

The following excerpts illustrate how the teacher's statement about ordering enabled the students to identify the core of their case quickly.

S1: Should we begin with questions relating to the circuit board? Is it defective?

S2: Yes, because it is the premise for everything.

S3: Yes, for all the other requirements

S2: For the broken car and the flight (...)

S4: Yes, the question is to what degree the car can be seen to be defective.

The group continues by summarising which statutes they have looked at and which sections deal with the issue of a defect in a consumer's purchase. They find two key statutes and focus on one of these. The following excerpt shows one student offering his reasoning: 
S1: If you start with the basic question, 'Is the car defective?', you can begin with $\S 15$ of the Consumer Purchase Act and sub-sections (a) to (c) and see what the conditions are for something counting as a defect.

Another student reports that he has considered $§ 17$ of the Consumer Purchase Act because it is relevant to sales in which there is an 'as is' clause, which applies in the vignette. Another student brings up $\S 18$ because it deals with 'latent defects'.

In summary, we see that the students engage in the practices of reading, exploring and discussing the statutes. The neatness of a chronological approach learned the day before and the teacher's new instructions facilitate progress. Gradually, the students come to understand that defectiveness is a concept with many elements, and that trust can be placed in statutory provisions. Thus, these provisions help the students to further sort the case by suggesting which of the factual details may be legally relevant.

\section{Day 3: Figures to trust: The courts}

In the teacher-led session the next day, the students' work is discussed, and their questions are elaborated on by Teacher 1 . The students are thereafter introduced to court decisions and told that this is another source of authority. Teacher 1 tells the students that the law may require new interpretations and that there may even be what he calls 'holes in the law' (loopholes) if the legislation does not cover the issue at hand. Moreover, with respect to the courts, the students are told that there is a clear hierarchy.

Two important Supreme Court decisions are introduced as potentially relevant to the case at hand: the 'rental car decision' and the 'video player decision'. The teacher advises the students to begin with the latter because it may provide them with further insight into the core question of what counts as a defect in the eyes of the law. The students are told that reading these cases is perhaps the most difficult task of the week because the text is often very dense. They are also reassured that the structure of decisions is often the same. Further, the teacher provides them with some basic rules regarding how to utilise this type of legal source. He states, 'You have to work purposively', and he continues to provide instructions about what that means. He tells the students that it is 'smart' to pinpoint the facts of the case or the 'story' first and then identify the legal issues. Ultimately, they must decide what the Court indicates as the basis for its ruling. 


\section{Student work}

In the subsequent group discussions, the students follow the teacher's instructions and commence with the so-called 'video player' case. After struggling for some time to understand the overarching principles contained in the judgment, the students begin to exchange ideas. However, it soon becomes apparent that they have not understood the significance of the judgment.

S4: But there are two quite different things here. The first case is about a video player that has a five-year warranty. (...) And in our case, the used car is now 11 years old, and I don't think these two situations are really comparable - an 11-year-old car versus a three-and-a-half-year-old video player!

S3: But it is not the car as such but the circuit board that was expected to last.

The students get back on track by reminding one another of their teacher's statements, i.e., his warnings about jumping to conclusions and his emphasis on the various purposes that Supreme Court cases can serve. They begin to look at the preparatory papers, which reveal that the video case judgment is not based on the Consumer Sales Act but rather extends it by specifying what 'acceptable quality' in a consumer purchase means. Furthermore, the notion of 'acceptable quality' takes into account what would normally be expected given the type of product in question and its cost. The students learn that what is crucial is not what one personally expects but what a reasonable person would expect of a used car. They identify the fundamental question: What level of performance is the purchaser of a used car entitled to?

In summary, we see how the students progressively enhance their ability to interpret authoritative sources and how the teacher's statements are helpful. The transition from the beginning of the independent learning session, which was characterised by an eagerness to jump to conclusions, to the careful analysis of the judge's argument towards the end is especially noteworthy.

\section{Day 4: Integrating the knowledge sources}

On the final day, Teacher 1 introduces the students to textbooks and tells them that they are one among many secondary sources of authority. He explains that although secondary sources are not binding, they can be useful in several ways. Because they have persuasive authority, they can be used to support a legal argument. Moreover, they offer

explanations and analyses of legal concepts. Thus, secondary sources also serve to further students' understanding of a particular legal problem. The teacher points out that court 
decisions are respected but can also inflame passionate disagreements. The students are thus advised to read various books in order to construct arguments.

\section{Student work}

The students share bits and pieces from the books they have read, denoting differences in viewpoints and ways of reasoning. A particular focus is placed on a core question that had vexed them during the week: Does an 'as is' clause invalidate the express promise of performance provided by the car salesman? They read in one of the textbooks that an express statement takes priority over a general term. The following extract illustrates how the students eventually demonstrate the capacity to move between the legal sources they had been introduced to in order to make connections, construct legal arguments and resolve their scenario.

S1: If you start with the basic question 'Is this a defective car?', you could start with Section $17 \mathrm{~b}$ of the Consumer Act.

S2: What does that say again?

S1: It says [reading aloud], if the conditions described in Section 16, subsection b or c, are fulfilled, Section 17 should apply.

S2: Yes, and in our case, they do!

S1: So then ... Section 17 takes you to 16 and back.

S2: Yes.

S1: Then, if you take into account that he [Gabriel] assented when he was asked whether the car could make it back and forth to Croatia, according to this book (pointing to a textbook), you can conclude that there is a defect.

In summary, we see that the students engage in the practice of using sources to make connections and construct arguments about the scenario. As a result of following the recommended step-by-step procedure, they no longer view the law merely as a fixed set of rules and are able to incorporate knowledge-related principles into practical work.

\section{Group 2}

\section{Day 1: Distinguishing signal from noise: 'Sorting' the case}

As with Group 1, this teacher-led session begins with introductions. The students describe why they applied to law school and the expectations they have. One notable feature is that Teacher 2 highlights the challenges of being a law student and includes tips and advice about critical issues in this respect, i.e. the desirability of establishing good 
study habits, the need to maintain a good work-life balance, and the importance of having a strategy for dealing with uninteresting subjects. Like Teacher 1, Teacher 2 informs the students of the aims of the course and provides them with an overview of the various sources of law. A significant difference between Teacher 1 and Teacher 2 is that the latter does not provide advice about how to sort the case.

\section{Student work}

The students begin with a conflict that involves the 17 -year-old boy, i.e., one that is peripheral to the central issue of the scenario. However, this triggers an interest in exploring the various sources:

S3: I thought a little about the boy and was eager to hear what you guys thought.

S2: I thought that the fact that the boy was only 17 would mean that his parents would be involved anyway as he is a minor, but I do not know the rules about this.

S2: I think the threshold for responsibility is 16.

The quotation below, from the end of the session, illustrates that the students did not know where to begin their analysis.

S1: Perhaps, we should have started with the car and then with the costs? Our approach has been a little at the wrong end.

In summary, we can observe that Teacher 2's reluctance to provide explicit directions weakened his influence on the students' work. One consequence was that they did not distinguish between relevant and irrelevant information, and this affected their ability to make progress on subsequent days.

\section{Day 2: Figures to trust: Legislators}

The day begins with the teacher asking the students to recall the distinction he made previously between the various types of legal authorities. As in Group 1, he reminds the students that the sources of law do not carry the same weight. Legislation is given priority, for example. He states that it is the professional community that decides what sources are trusted and considered relevant.

He then turns his attention to the students' work completed the day before. Despite the fact that Teacher 2 had not given it to them as an explicit task, he proceeds by asking them what legal disputes arise from the vignette and who the parties are. Interestingly, the students are able to identify the disputants. Next, he introduces them to their new task, which is to find the law that is applicable to the scenario. He briefly 
outlines how the statute book is organised and how the material can be read. In addition, he devotes time to describing how to use post-it stickers to locate materials quickly. In contrast to Group 1, in which the teacher underlined the importance of both sorting and sequencing, Teacher 2 does not provide guidance regarding the chronology of the analysis.

\section{Student work}

With no guidance from the teacher regarding where to start, the students again begin considering the role of the 17-year-old boy who stole and damaged the car. They locate the Damages Act and discuss whether the teenager has financial resources, whether the parents are responsible, and what compensation may be available. This leads to a discussion regarding what laws are relevant to the task. The students then turn their attention to the conflict between Gabriel and Tine and Hallvard and recall the laws they have read that relate to this dispute. Although they have identified a range of statutes they believe may be relevant, they struggle to determine how to unravel the conflict.

The excerpt below illustrates not only this struggle but also how one student manages to bring the discussion back on track by suggesting that they begin with the chapter that sets out the criteria for determining what constitutes a defect:

S2: So a central question is whether it is their fault or his. That the car is damaged, I mean.

S4: Yes, but it is hard to really know because the car just broke down, and it does not say anything ... about it being treated badly.

S3: I think we need to find out if the car is defective first.

The discussion continues, but the input of S3 is ignored. However, S3 is insistent and returns to his concern several times. A turning point comes when he observes that the question of who is responsible for a fault is only relevant if the car has a defect.

Eventually, after taking his point, the students spend the rest of the session exploring what amounts to a defect and how the criteria stated in the various acts may inform their case.

In summary, we see that without further guidance about how to sort the case, the students struggled to grasp that the concept of defectiveness is statutorily defined. Thus, they were working with irrelevant information, and their progression depended on a single persistent student getting them on track. It is only at the end of the session that the students engage in sorting practices relating to what constitutes a defect.

\section{Day 3: Figures to trust: The courts}


This teacher-led session begins with a recap of all the legal sources and some indications as to how they are weighted. The teacher then goes on to discuss the role of the Supreme Court and explain the structure of a court decision. He also dwells on the themes of unanimity and disagreement in the Supreme Court and points out that a decision can be trusted even if a minority opinion is expressed. He concludes by giving the students some pointers about how to open up the scenario, telling them to focus on what the Supreme Court decides. Unlike Teacher 1, Teacher 2 does not tell his students which case to begin with or even alert them to the fact that one of the judgments relates to the core issue of defect while the other deals with the rules on compensation.

\section{Student work}

In this session, one of the students asks which judgement they should begin with. S3 suggests that they should commence with the video player judgment. However, the other students decide to start with the rental car decision because it is easier to read. After debating the latter case, they turn their attention to the video player judgment. The students do not focus on the meaning of 'defect' but again draw parallels between the two cases regarding the compensation that may be available.

The students attempt to determine whether the cases have something in common despite the obvious differences between a new video player and a used car. Their work is impeded by the fact that they use the Sale of Goods Act without understanding that the video player case identifies a loophole in that statute.

Towards the end of the session, S3 tells the other students that he believes the essence of the judgement is the definition of what level of performance the purchaser of goods is entitled to:

S3: We have to bear in mind that at this point in time, the Consumer Purchase Act did not exist.

S1: No? Then, we only had the Sale of Goods Act, right?

S1: Yes, I wondered about that because we decided it was a consumer purchase, so what happened?

S3: I am pretty sure that the (video player judgement) contributed to the development of the Consumer Purchase Act.

Student 3 is then asked by the other students what he learned and replies: 'What I felt I got out of reading the case is what one can expect from an ordinary item you purchase and that you have a right to expect things'. Convinced by this, towards the end of the session, the other students begin to investigate the essence of the case and thus engage in a new line of inquiry that is more on-target. 
In summary, the students know the figures to trust, but their work ground to a halt as they did not understand how to use the materials produced by the trusted sources. By way of contrast, in Group 1, a structure was provided by the teacher in the form of cues regarding how to sort the material.

\section{Day 4: Integrating the knowledge sources}

The final session begins by discussing what textbooks are and what type of authority they have. Similar to Teacher 1, Teacher 2 explains that textbooks are only a theoretical elaboration of the statute book. He informs the students that, as secondary sources, textbooks carry little weight in court but may have an indirect influence because legislators and judges may value the views and arguments contained in the literature. He also warns that textbooks can be deceptive because they typically make complicated issues seem simple. He recommends that the students acquire several different books but advises them not to read them from cover to cover because that could potentially divert their attention from the exploration of other sources.

\section{Student work}

The students start the session by reflecting on what the task is and how far they have progressed in resolving the scenario. They use the textbooks to understand the basics and begin to understand the complexities involved in the legal definition of a defect:

S2: Finally, I have found something about a used car so now we can get the answers to the questions we have wondered about or at least some of them.

After S2 shows the other students the part of the book he is referring to, the discussion continues:

S4: It says here that not all hidden defects amount to a breach of the seller's obligations, so we can maybe conclude that the defect may not be the seller's responsibility.

S2: No. There is a lot here and in other chapters about how the price of goods should be taken into consideration and what quality one is entitled to expect.

In summary, the students in Group 2 use only textbooks to understand the basic legal issues in the case scenario and seem less competent than Group 1in bringing all the materials they were presented with together. Nevertheless, there is evidence from their 
work that the students in Group 2 appreciate the value of the core practices required to perform as a professional.

\section{Discussion}

Our analyses show the way students' work was influenced synergistically by the course design and the ways in which the teachers introduced the three core practices critical for professional performance. In relation to our first research question, we can see from the material gathered in the preparatory meeting and the discussions there, that the course was designed to provide an in-depth explanation of each core practice up front. The overall course design implied that each day started with a (re)opening of the case and ended with the students suggesting a (preliminary) solution. On the following day, this solution was then debated in the colloquium session and a new source was introduced. While the students focused on one type of epistemic practice at a time, they also contributed insights they had obtained from one day to the next and gradually improved their understanding of the scenario. Thus, the course made visible 'the strategies and policies of knowing that are not codified in textbooks but do inform expert practice' (Knorr Cetina 1999, p. 2).

Regarding our second research question, our analyses of the material gathered from the "colloquiums" and independent student group discussions underline the core role teachers play in making these strategies and policies clear. With respect to the three core archetypes of epistemic practices, we can see that the teachers' inputs to their groups specify which figures to trust and how to make use of the materials they produce. By highlighting the roles of various actors, such as lawmakers and the Supreme Court, the teachers introduced the students to the resource relationships that facilitate and maintain the ordering structures upon which the legal profession relies. In addition, the roles of sorting and practical know-how were revealed, including how they serve as important mediating devices in student learning. Briefly put, during each day, we can see how sorting mediates between knowing activities and how it conditions and determines acts of signification.

With respect to the third research question, the findings from the comparative analysis highlight that the students' activities varied with regard to focus and structure and were shaped by how the inquiry process was guided and supported and the way the core practices were introduced. Hence we see that despite the tight script, the exercise of influence of the teacher is important. For instance, in Group 1, we can see how the approach to breaking down and sorting the case on the first day led the students into a more structured investigation of the legal issues involved. Similarly, the teacher's introduction to reading the law on the second and third days highlighted the importance of detailed legal reading and helped them to further sort the case. For example, while 
reading the statutes, they saw that factors related to the conditions of the sale were relevant and had to be considered in discerning whether the car was defective. Likewise, reading the video player judgment led them to explore the condition of the car itself, i.e. how old it was, what make it was, etc. Here, we see how facts acquired meaning through their legal context. This is important because, as pointed out by Latour, 'facts are like trains, they do not work off the rails' (1983, p. 266). In addition, new questions and avenues for exploration can emerge from the stabilising effects of eliminating 'noise'. On the last day, we can see how the knowledge gained was transported back into the complexity of the real world.

Compared to Teacher 1, Teacher 2 offered his group less structure regarding how to approach the case scenario in terms of sorting practices. These contrasting approaches also had implications for how the students' knowledge-building processes evolved. Group 2 was unable to sort the case and therefore struggled to deal with the 'noise' contained in the scenario, which impeded their learning progress. Hence, we can see how practices that can be clustered around the term 'sorting' are an important aspect of the inquiry process because they allow the differentiation of the relevant from the not so relevant. In this way, sorting allows students to make small decisions that are necessary for progress. Additionally, we can see how developing relationships with knowledge is a process and how the teacher's contributions at the beginning and end of each session, together with the overall course design and its temporal arrangement, provided structure for the students' explorations. Moreover, we observed how learning takes place in what Knorr Cetina termed 'the unfolding structures of absences' (Knorr Cetina 2001, p., 528). What is important to note here is that the teacher's statements first served as a forward feed to get processes going - the students encountered learning gaps, and it was within these gaps that the teacher's elaborations and statements had impact. Hence, both forward and backward feeds are required to engage students in productive learning loops.

A final issue relates to the question of agency and the discrepancy between being a novice and being an expert regarding the task of representation. To represent, as Pels (2001) pointed out, entails speaking for a community with authority - to be what he called a 'spokesperson'. While teachers have documented their mastery of the core practices of the profession, students have not. This is illustrated in Group 2, in which a student who had some previous knowledge of law repeatedly attempted to bring his colleagues back on track. However, his voice was not 'strong enough' to command the attention of the other students. Although one of the strengths of PBL is that, as with other inquiry-based models for learning, it re-focuses education on the student (Markham 2011), our study suggests that outsourcing too much responsibility to students may be detrimental.

\section{Conclusions and further research}


Our study brings into focus how PBL may enhance the relationship between school and work and, more specifically, serve the purpose of a practical apprenticeship. In line with Akkerman and Bakker (2012) and as illustrated through the examples presented here, creating connections between education and work may not be a question of overcoming the differences between socially and culturally shaped learning sites, but rather a matter of creating continuity between the types of practices focused on in workplaces and education. Thus, we conclude that the three core practices described and their logics must be taken seriously in the design of future PBL courses if they are to serve as practical apprenticeships.

We suggest two pathways for further advancement. The first pertains to research while the second concerns design of PBL courses more generally. Our empirical focus has been limited to an introductory course in legal education where the figures to trust are immutable. A suggestion for further research would be to investigate professional fields where the authoritative sources are not necessarily fixed and are thus more contestable; for example, teaching and nursing. In such cases, professional schools may need to involve many stakeholder groups in order to design a curriculum that bridges education and work. We also recognize that over time the results of teaching may manifest themselves in a different way than that suggested in this article. Hence, studies with a longitudinal design may provide slightly different results to those found here. Lastly, we suggest possible contributions of a practice -based perspective with respect to opening up new designs for PBL courses and new ways of conceptualizing educational support for professionals more generally. First, this perspective highlights the critical role "know- how" plays in the development of professional expertise and underlines the need to think more carefully about this aspect of the growth of expertise than has previously been the case. Second, a practice -based approach implies recognizing that, no matter how tightly scripted a technology is, it will always allow for variation when it is enacted. Hence the teacher's influence is critical. Third, by highlighting what is often invisible in the dynamics of professional learning it invites a broader vision of teaching than that which has characterized the literature to date. Rather than invite discussions of front or back loading of teaching sessions, it encourages a view of teaching as a question of attunement to things seen and unseen, a sensibility to what may be distinct about a domain, or a sense of knowing and understanding tricks of the trade. Thus our final thought is that the epistemic perspective has much to offer not only as a research tool but also as a design tool with respect to the use of PBL on introductory courses.

\section{Funding}


This research was conducted as part of the project, Horizontal Governance and Learning Dynamics in Higher Education, funded by the Research Council of Norway under the FINNUT programme (2012-2016).

\section{References}

Akkerman, S. F., \& Bakker, A. (2012). Crossing boundaries between school and work during apprenticeships. Vocations and Learning, 5, 153-173.

Akrich, M., \& Latour (1992). A Summary of a Convenient Vocabulary for the Semiotics of Human and Nonhuman Assemblies. In Wiebe E. Bijker and John Law (eds.), Shaping Technology/Building Society: Studies in Sociotechnical Change, Cambridge, Mass.: The MIT Press, 259-264.

Barrows, H. S. (1986). A taxonomy of problem-based learning methods. Medical Education, 20, 481-486.

Billett, S. (2001). Learning in the workplace: Strategies for effective practice. Sydney: Allen \& Unwin.

Billett, S., \& C. Billett, S. (2010). Vocational learning: Contributions of workplaces and educational institutes. In R. Maclean \& D. Wilson (Eds.), International handbook of education for the changing world of work: Bridging academic and vocational learning (pp. 1711-1723). Bonn, Germany: Springer Science.

Billett, S., \& Choy, S. (2013). Learning through work: Emerging perspectives and new challenges. Journal of Workplace Learning, 25(4), 264-276.

Boud, D., \& Feletti, G. (Eds.). (1997). The challenge of problem based learning (2nd ed.). London, UK: Kogan Page.

Damşa, C. I., Nerland, M. \& Jensen, K. (2017). Enrolment of higher education students inknowledge domains - An analysis of transformative practices in three introductory courses, In E. Kyndt, V. Donche, K. Trigwell, S. Lindblom-Yllane (Eds.) Higher EducationTransitions: Theory and research. London: Routledge - Taylor \& Francis group.

Guile,D. \& Griffith, T. (2001). Learning through work experience. Journal of Education and Work, 14(1), 113-131.

Hmelo-Silver, C., Duncan, R., \& Chinn, C. (2007). Scaffolding and achievement in problem-based and inquiry learning: A response to Kirschner, Sweller, and Clark (2006). Educational Psychologist, 42(2), 99-107. 
Hmelo-Silver, C. E., \& DeSimone, C. (2013). Problem-based learning: An instructional model of collaborative learning. In C. E. Hmelo-Silver, C. A. Chinn, C. K. K. Chan, \& A. O'Donnell (Eds.), The international handbook of collaborative learning (pp. 370-385). New York: Routledge

Hoidn, S. \& Kärkkäinen, K. (2014). Promoting skills for innovation in higher education: A literature review on the effectiveness of problem-based learning and of teaching. OECD Education Working Papers, No. 100, OECD Publishing.

Knorr Cetina, K. (1999). Epistemic cultures: How the sciences make knowledge. Cambridge, MA: Harvard University Press.

Knorr Cetina, K. (2001). Objectual practice. In T. Schatzki, K, \& E. von Savigny (Eds.), The practice turn in contemporary theory (pp. 175-188). London and New York: Routledge.

Knorr Cetina, K., \& Reichmann, W. (2016). Professional epistemic cultures. In I. Langemeyer, M. Fischer, \& M. Pfadenhauer (Eds.), Epistemic and learning cultures woher und wohin sich Universitäten entwickeln (pp. 18-33). Weinheim: Juventa Verlag.

Latour, B. (1983). 'Give me a laboratory and I will raise the world'. In K. Knorr Cetina and M. Mulkay (Eds.), Science observed: Perspectives on the social study of science (pp. 140-170). London and Beverly Hills: Sage.

Latour, B. (2010). The Making of Law: An Ethnography of the Conseil d'Etat. Paris: Polity Press

Loyens, S. M. M., \& Rikers, R. M. J. P. (2011). Instruction based on inquiry. In R. E. Mayer \& P. A. Alexander (Eds.), Handbook of research on learning and instruction (pp. 361-381). New York: Routledge.

Markham, T. (2011). Project based learning. Teacher Librarian, 39(2), 38-42.

O’Mahony, T. K., Vye, N. J., Bransford, J. D., Sanders, E. A., Stevens, R., Stephens, R., et al. (2012). A comparison of lecture-based and challenge-based learning in a workplace setting: Course designs, patterns of interactivity, and learning outcomes. The Journal of the Learning Sciences, 21, 182-206.

Newman, M. (2003). 'Special Report 2: A pilot systematic review and meta-analysis on the effectiveness of Problem Based Learning'. ITSN Learning and Teaching Support Network. Middlesex University, UK.

Pels, R. (2001). The intellectual as stranger: Studies in spokespersonship. London: Routledge. 
Schmidt, H. G., Rotgans, J. I., \& Yew, E. H. J. (2011). The process of problem-based learning: What works and why. Medical Education, 45(8), 792-806.

Schulman, L. S. (2005). Signature pedagogies in the professions. Dædalus, 134(3), 5259.

Williams, S. M. (1992). Putting case-based instruction into context: Examples from legal and medical education. The Journal of the Learning Sciences, 2, 367-427. 